\title{
CIÊNCIAS NO NONO ANO DO ENSINO FUNDAMENTAL: DA DISCIPLINARIDADE À ALFABETIZAÇ̃̃O CIENTÍFICA E TECNOLÓGICA
}

\author{
Tathiane Milaré* \\ José de Pinho Alves Filho**
}

RESUMO: Este artigo discute as características do Ensino de Ciências desenvolvido na última série do ensino fundamental na disciplina Ciências. Apresenta uma análise do que é oferecido pelos livros didáticos e o que efetivamente os professores abordam quando tratam de Química com seus alunos. Os resultados indicam que a Química é tratada disciplinarmente, contrapondo-se à interdisciplinaridade e à contextualização necessárias nesta fase do ensino. Como proposta para possível reversão da situação constatada, são apresentados alguns pontos a serem considerados no programa escolar de Ciências para a promoção da Alfabetização Científica e Tecnológica, utilizando como exemplo a abordagem do tema Leite.

Palavras-chave: Ensino de Ciências; Alfabetização Científica e Tecnológica; Nono Ano.

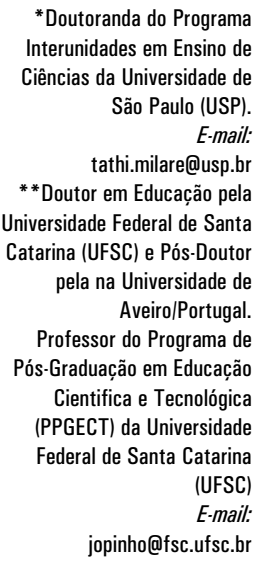

SCIENCE EDUCATION IN THE $9^{\text {TH }}$ GRADE OF THE ELEMENTARY SCHOOL: FROM DISCIPLINARITY TO SCIENTIFIC AND TECHNOLOGICAL LITERACY

ABSTRACT: This article discusses a few characteristics of the Science Education developed in the last series of the elementary school. It also analyzes the adopted Science textbooks and what Chemistry contents are taught for students in the 9th grade. The analysis of these issues shows that in Science, the Chemistry is worked disciplinarily, contrasting to the interdisciplinarity and contextualization needed for the citizenship development during basic school. As proposed, we present a few points to be considered for the school program of science with a view to promote Scientific and Technological Literacy, having the theme Milk as an example.

Keywords: Science Education; Scientific and Technological Literacy; Ninth Grade.

\section{Introdução}

O programa escolar do nono ano do ensino fundamental, em geral, é constituído por conteúdos de Química e Física que são divididos entre os semestres do ano letivo. Tais conteúdos são desenvolvidos como se fossem disciplinas separadas e desconexas, apesar de serem ministradas pelo mesmo professor - a maioria formada em Ciências Biológicas - e se tratar da disciplina anual de 
Ciências. Trata-se de uma antecipação da abordagem disciplinar das Ciências que deveria ocorrer apenas em fases posteriores do ensino.

Diante desse contexto, analisamos os direcionamentos apresentados para o Ensino de Ciências em documentos oficiais como a Lei de Diretrizes e Bases da Educação Nacional, os Parâmetros Curriculares Nacionais (PCNs) e as Propostas Curriculares dos Estados de Santa Catarina e de São Paulo (MILARÉ, 2008). A finalidade foi a de destacar os principais aspectos sugeridos nestes documentos, buscando proximidades e distanciamentos com pesquisas desenvolvidas sobre o Ensino de Ciências do nono ano.

Após a verificação das tendências dos documentos oficiais e das pesquisas em ensino, buscamos compreender o que ocorria em um contexto mais próximo da prática escolar nas aulas de Ciências. Para isso, foram caracterizados e discutidos os conhecimentos de Química presentes em livros didáticos indicados pelo Programa Nacional do Livro Didático 2005 (PNLD). Os conteúdos trabalhados em classes de nono ano também foram considerados, utilizando-se de entrevistas com professores de Ciências de escolas públicas de Florianópolis, SC, e de Araraquara, SP.

Com base nos dados levantados, uma proposta de ensino foi desenvolvida com a finalidade de contribuir para com a Alfabetização Científica e Tecnológica (FOUREZ, 1997) dos concluintes do ensino fundamental. Desta forma, o objetivo deste trabalho é apresentar uma análise geral do Ensino de Ciências do nono ano, destacando quais e como os conhecimentos de Química são abordados, e discutir uma proposta de como a Química pode contribuir com o processo de Alfabetização Científica e Tecnológica (ACT) para a formação da cidadania dos estudantes.

\section{Origens da Química e da Física no nono ano e as tendências atuais}

Ensinar Química e Física na última série do ensino fundamental é uma proposta herdada das finalidades do ensino de meados do século XX, quando até então houve, oficialmente, a predominância do modelo tradicional de ensino caracterizada pela transmissão-recepção de informações. Nesse modelo, as informações e os conceitos eram fragmentados, estanques e reunidos em "grandes pacotes temáticos correspondentes à Física, Química, Biociências, Geociências" (AMARAL, 2000, p. 213).

No Brasil, a intervenção mais efetiva do Estado na organização da educação ocorreu no período do Estado Novo, de 1937 a 1945, que levou à criação das Leis Orgânicas do ensino para os níveis secundário e primário, correspondentes ao atual ensino básico (ZOTTI, 2006). Nesse período, definiu-se a obrigatoriedade da disciplina de Ciências para as terceira e quarta séries do curso ginasial (atuais oitavo e nono ano do ensino fundamental), assim como os conteúdos mínimos para cada série. Em linhas gerais, para a terceira série do curso 
ginasial, foram definidos os conteúdos sobre a Água, Ar e Solo, noções de Botânica e de Zoologia e o Corpo Humano e, para a quarta série, noções de Química e de Física (DOMINGUES; KOFF; MORAES, 2000). Quando o Ensino de Ciências passou a permear as demais séries do correspondente ao ensino fundamental atual, estes conteúdos foram distribuídos entre elas: Água, Ar e Solo para o sexto ano; Botânica e Zoologia para o sétimo ano; Corpo Humano para o oitavo ano e, finalmente, Química e Física para o nono ano.

Desta época aos dias atuais, ocorreram reestruturações na educação brasileira que repercutiram também no Ensino de Ciências. O caráter mais prático do ensino, a participação e o cotidiano dos alunos passaram a ser mais valorizados. As questões ambientais e a interdisciplinaridade ganharam espaço nos programas escolares e a Ciência passou a ser apresentada como um processo, pelo menos nos documentos e discurso das autoridades e professores. Hoje temos propostas curriculares nacionais (BRASIL, 1996) e estaduais como as do estado de Santa Catarina (1998) e de São Paulo (2008), entre outras, que enfatizam a necessidade da abordagem interdisciplinar, em detrimento do estudo dos conteúdos de forma fragmentada.

Com exceção de um pequeno trecho da Proposta Curricular de Santa Catarina - aliás, contraditório e não condizente com o restante do texto (SANTA CATARINA, 1998, p. 121) -, os documentos não orientam a abordagem disciplinar da Química e da Física no nono ano. Ao contrário, sugerem o entrelaçamento das diversas áreas da Ciência. Nesta perspectiva, os conhecimentos de Física e de Química contribuem para com o entendimento de situações significativas, independentemente da disciplina e da série em que a situação é explorada.

Atrelada à interdisciplinaridade, a abordagem temática também se faz presente nas diretrizes. Pela problematização de temas, é possível contextualizar os conhecimentos científicos e aproximá-los da realidade dos alunos. Trata-se de uma forma de atribuir sentido aos conceitos que poderão ser utilizados na vida dos estudantes. É importante lembrar, porém, que os temas não devem abranger somente o cotidiano dos alunos, mas, também, considerar as situações importantes para a sociedade como um todo. Alguns temas como, por exemplo, a influência do homem no meio ambiente e os processos de obtenção de energia, são sugeridos, não só nos estados de Santa Catarina e São Paulo, como também em todo o país, por meio dos PCNs. Isso porque são temas importantes para o futuro da humanidade, em qualquer parte do mundo.

Outro aspecto importante e comum em todos os documentos analisados é o papel que o conhecimento científico possui na promoção da cidadania, entendida como a capacidade de um indivíduo de participar e compreender seu papel na sociedade, refletindo criticamente sobre situações diversas com as quais se depara ao longo da vida. Aprender Ciências deixa de ser apenas uma obrigação escolar pela qual os alunos buscam para passar de ano, e transforma-se em uma ferramenta para entender o mundo de outra forma.

Além das diretrizes apresentadas, trabalhos fundamentados na pesquisa têm mostrado outras importantes iniciativas na reestruturação do Ensino de 
Ciências no ensino fundamental (LIMA; SILVA, 2007; MALDANER, et al., 2007). Pontos comuns podem ser extraídos destes trabalhos e dos documentos oficiais e, de modo geral, ilustram algumas tendências para o Ensino de Ciências. São elas: (a) Preocupação com as concepções dos estudantes sobre conceitos científicos; (b) Foco na formação da cidadania; (c) Oposição ao ensino tradicional que considera o aluno passivo em sua aprendizagem; (d) Abordagem interdisciplinar; (e) Uso racional, crítico e limitado do livro didático; (f) Introdução de discussões sobre aspectos sociais, políticos e econômicos; $(\mathrm{g})$ Uso de temas relevantes na sociedade moderna; (h) Uso de textos, atividades experimentais e outras e (i) Participação efetiva dos alunos em sala de aula (MILARÉ, 2008).

Mesmo com o aparente consenso a respeito desses aspectos, algumas contradições ainda persistem. Ao avançar nas fases escolares, os estudantes deparam-se, cada vez mais, com um ensino fragmentado, apesar do discurso a favor de uma abordagem interdisciplinar e contextualizada. Os programas escolares de Ciências do nono ano de muitas escolas são exemplos disso, pois sua formatação baseada na Química e na Física separadamente ainda permanece. É o que pode ser constatado nos livros de Ciências e no trabalho dos professores e que será apresentado a seguir.

\section{A Química nos livros didáticos de Ciências}

Os livros recomendados e escolhidos pelos professores são distribuídos às escolas públicas e, basicamente, servem de referência para a elaboração do programa escolar. Conhecer quais e como os conteúdos de Química são apresentados nos livros do nono ano é um meio de obter indicativos sobre as possíveis influências do livro didático no Ensino de Ciências. Foram analisados oito livros, escolhidos com base na indicação do PNLD 2005, utilizando, como metodologia, a Análise de Conteúdo descrita por Bardin (1977).

Os capítulos referentes aos conhecimentos de Química foram lidos, com exceção das atividades propostas. Também foram consideradas as unidades de introdução à Física e à Química, que traziam conceitos importantes para o estudo destas Ciências. Independentemente da forma de apresentação destes conhecimentos, os assuntos ou tópicos de Química foram sendo anotados para cada livro.

Foram encontrados 47 tópicos de conteúdos de Química nos livros (Quadro 1). Entre eles, a maioria (cerca de 74,5\%) está presente em mais da metade dos livros, indicando que os livros de Ciências apresentam uma base comum. 
Quadro 1: Conteúdos referentes à Química encontrados nos livros analisados

\begin{tabular}{|c|c|}
\hline Tópicos de Conteúdos & $\begin{array}{l}\text { Total de Livros em que } \\
\text { foram encontrados }\end{array}$ \\
\hline Número Atômico; Número de massa; Elementos químicos; Classificacão dos elementos; Tabela Periódica. & 8 \\
\hline $\begin{array}{l}\text { Transformações físicas e químicas; Modelo atômico Dalton; Modelo atômico de Rutherford-Bohr; Distribuição } \\
\text { eletrônica; Íns; Ligação lônica; Ligação Covalente; Ácidos; Bases; Sais; Óxidos; Substâncias } \\
\text { (molecular, iônica, simples, composta); Equações químicas; Leis das reações. }\end{array}$ & 7 \\
\hline $\begin{array}{l}\text { Mudança de estados físicos; Modelo atômico de Rutherford; Isótopos; Radioatividade e energia atômica; } \\
\text { Misturas; Separação de misturas; Fórmulas. }\end{array}$ & 6 \\
\hline $\begin{array}{l}\text { Matéria (definição, exemplos); Energia (definiçã̃o, exemplos); Estados Físicos; Propriedades da matéria } \\
\text { (Gerais e Específicas); Modelo atômico de Thomson; Ligação Metálica; Alotropia; } \\
\text { Balanceamento de equações; Tipos de reações. }\end{array}$ & 5 \\
\hline Massa atômica; Isóbaros; Velocidade das reações. & 4 \\
\hline $\begin{array}{l}\text { Química (apresentação da Ciência, histórico, relação com a sociedade); } \\
\text { Átomos e moléculas (abordagem inicial); Isótonos. }\end{array}$ & 3 \\
\hline $\begin{array}{l}\text { Massa molecular; Soluções (tipos) ou solubilidade; Substâncias } \\
\text { (naturais, sintéticas, orgânicas e inorgânicas); Ciclos biogeoquímicos. }\end{array}$ & 2 \\
\hline Tensão superficial; Funções orgânicas. & 1 \\
\hline
\end{tabular}

As recomendações dos PCNs de que explicações de fenômenos no nível molecular e atômico devem ser evitadas (BRASIL, 1998), não são consideradas na maioria dos livros, como é possível observar pelos tópicos de conteúdos encontrados. Boa parte deles necessita de uma compreensão detalhada do mundo microscópico, como é o caso dos Modelos Atômicos, Distribuição Eletrônica, Íons, Número Atômico e de Massa, Massa Atômica e Molecular, Isótopos, Isóbaros e Isótonos, Radioatividade, Ligações Químicas, Alotropia, Funções Orgânicas, entre outros. Diversas pesquisas, com estudantes do ensino médio (MORTIMER, 1995; ROSA; SCHNETZLER, 1998; FURIÓ, Carlos; FURIÓ, Cristina, 2000), mostram que a construção de muitos destes conceitos e a relação entre os mundos macro e microscópico representam uma das maiores dificuldades do processo de aprendizagem em Química. Entre os estudantes do ensino fundamental, estas dificuldades são ainda maiores, pois os conceitos são apresentados sem estimular a compreensão de tais relações. Além disso, o estudo dos conceitos químicos no ensino fundamental é feito em uma carga horária reduzida, dentro do Ensino de Ciências do nono ano e, em geral, por um professor sem a formação e/ou conhecimento adequados.

Considerando o grau de complexidade e de abstração que alguns conteúdos de Química podem alcançar, dependendo da profundidade trabalhada, é necessário cuidado do professor na abordagem destes conteúdos. É interessante admitir algumas limitações no desenvolvimento de alguns conhecimentos em Química no nono ano como, por exemplo, as equações químicas que "ainda devem ser abordadas de modo qualitativo, considerando-se quais os reagentes, as condições da reação e seus produtos, o que já é suficientemente difícil para este grau de escolaridade" (BRASIL, 1998, p. 98). O que se espera dos estudantes é que eles iniciem o desenvolvimento de um "pensamento químico" e não sejam forçados a compreender e memorizar detalhes de complexos modelos químicos. 
É necessário lembrar que os conteúdos presentes nos livros de Ciências também estão presentes nos livros de Química do ensino médio. A apresentação dos conteúdos nestes dois tipos de livros é bastante semelhante (MILARÉ, 2005).

Além de quais conteúdos de Química estão presentes nos livros, buscamos avaliar de que forma eles são apresentados, conforme as seguintes questões de análise:

(a) há direcionamento do conteúdo para a compreensão de algum fenômeno do cotidiano?; (b) a história e/ou o desenvolvimento da Ciência e/ou da Tecnologia são considerados em algum momento da abordagem dos conteúdos? e (c) algum aspecto relacionado à economia, à sociedade, à política, à ética, ao meio ambiente, à moral, ao trabalho, à saúde ou à cultura é abordado?

Os resultados da análise mostraram que a grande maioria dos conteúdos de Química nos livros de Ciências analisados é abordada de maneira fragmentada, sem relação com outras áreas da Ciência e situações reais vividas pelos estudantes na sociedade.

\section{O Cotidiano e os conteúdos de Química}

Há conteúdos de Química, em todos os livros analisados, que estão desvinculados de qualquer tipo de exemplo que fizesse uma aproximação entre aquilo que é estudado e a vida dos estudantes. Não se verifica inserção por meio de temas relevantes ou referências ao cotidiano. A apresentação é realizada por meio de conceitos e modelos de como aplicá-los em exercícios, dentro da própria teoria estudada, sem extrapolar as ideias trabalhadas para situações mais reais ou mais próximas dos estudantes. Entre estes conteúdos estão os Modelos Atômicos, Distribuição Eletrônica, Íons, Números Atômicos e de Massa, Massa Atômica e Molecular, Isótonos e Isóbaros, Fórmulas Químicas e Balanceamento de Equações. Algumas vezes, a abordagem destes conteúdos é justificada no próprio livro como sendo essencial no estudo da Química no ensino médio, o que justificaria os estudantes do ensino fundamental estudá-los para posterior aprofundamento.

O único conteúdo de Química relacionado ao cotidiano em todos os oito livros é a Classificação dos Elementos em metal, não-metal, semimetal e gases nobres. Existe, porém, pouca variedade de situações cotidianas e os exemplos são semelhantes em todos os livros.

As relações entre o cotidiano e os conteúdos de Química, embora sejam raramente apresentadas, são válidas no sentido de mostrar aos alunos aplicabilidade do que aprendem. Porém, ainda não é o suficiente. Em média, cerca da metade dos conteúdos de Química estão desvinculados do cotidiano ou outra forma de contextualização. $\mathrm{O}$ estudante dificilmente consegue fazer sozinho uma ligação entre os conceitos e seu dia-a-dia, se eles iniciam e terminam em si mesmos. Com os professores não é diferente! Quanto mais abordagem do coti- 
diano e mais contextualizados os conteúdos dos livros didáticos, maior será a probabilidade destas relações também serem feitas em sala de aula e melhor compreendidas pelos estudantes.

\section{História e desenvolvimento da Ciência e da Tecnologia}

Os aspectos históricos da Ciência encontrados nos livros analisados concentram-se, principalmente, no desenvolvimento das teorias atômicas e da Tabela Periódica. Em geral, os livros apresentam informações sobre como, quando e a importância de cada modelo desenvolvido. Dos oito livros analisados, sete trazem esta abordagem para ambos os assuntos. O mesmo ocorre com o histórico da evolução do conceito de Elemento Químico e das Leis de Proust e Lavoisier presente em seis livros.

Referências à História da Química aparecem em apenas três livros. Abordagens pontuais do desenvolvimento de Tecnologias também são feitas em poucos livros.

A introdução de aspectos históricos do desenvolvimento da Ciência e da Tecnologia no Ensino de Ciências pode enriquecer os conteúdos desenvolvidos, estimular o interesse dos alunos e ajudá-los a compreender o processo de produção do conhecimento e sua relação com a sociedade. Nos livros analisados, porém, são muito pouco explorados.

\section{Aspectos da vida cidadã}

A análise destes aspectos nos livros didáticos mostrou que os assuntos relacionados à Radioatividade são os que concentram a maior parte dos aspectos sociais, ambientais, econômicos e políticos. $\mathrm{Na}$ grande maioria das vezes, o tema é desenvolvido em textos complementares ou caixas de texto separadas do capítulo e apresenta acontecimentos da Segunda Guerra Mundial, do acidente de Goiânia com o Césio 137 e de Chernobyl.

Os danos ao ambiente causados pela ação humana são discutidos em todos os livros analisados. A abordagem dos ácidos, por exemplo, remete a maioria dos livros a discutirem o fenômeno da chuva ácida e suas implicações para o meio ambiente.

Outros temas identificados e relacionados aos aspectos da vida cidadã são: relação da Química com a sociedade, segurança no trânsito, mineração, polímeros, armas químicas, qualidade da água, uso de drogas, cálculo renal, descarte de pilhas, produção de energia, reciclagem e efeito estufa. Infelizmente, muitos desses temas são abordados sem relação direta com os conteúdos. Isso evidencia a falta de conectividade entre os conhecimentos científicos apresentados e a implicação na vida dos estudantes. 
Uma vez conhecido o quê e como a Química está presente nos livros, veremos como é o trabalho de nove professores em relação a esses conhecimentos.

\section{Em busca do que os professores abordam}

Foram entrevistados cinco professores de Florianópolis, SC, e quatro professores de Araraquara, SP. Entre os professores entrevistados, sete possuem formação inicial na área de Ciências Biológicas e dois são licenciados em Química. Apenas dois dos professores entrevistados não possuíam algum curso de pós-graduação (mestrado ou especialização lato senso).

Os professores foram questionados sobre a abordagem da Química no nono ano e, diante de um quadro com os tópicos de conteúdos encontrados nos livros didáticos, puderam assinalar quais desenvolviam em sala de aula com seus alunos.

Todos eles dividem o ano letivo principalmente entre os conteúdos de Química e de Física. É notável a quantidade de tópicos de conteúdos assinalados pelos professores. Com exceção de um professor, licenciado em Química, os demais trabalham praticamente todos os conteúdos presentes nos livros didáticos (MILARÉ; PINHO-ALVES, 2010b).

O livro didático continua influenciando o trabalho realizado em sala de aula, apesar de apenas um dos professores consultados ter admitido isso. Um indicativo é o fato dos conteúdos desenvolvidos no nono ano serem de Química e de Física separadamente, uma vez que esta recomendação não foi encontrada nos documentos oficiais. Nesse sentido, a análise dos livros didáticos de Ciências foi importante para verificar os conteúdos lecionados e de que forma são apresentados ao professor e aos alunos que os utilizam.

A maioria dos professores concorda que existe um excesso de conteúdos. Por outro lado, alguns deles não modificariam o programa escolar de imediato, mas sim o número de aulas de Ciências. Ao opinarem sobre os conteúdos de Química, dois professores relataram a necessidade de aumentar a carga horária, admitindo a impossibilidade de isso ocorrer.

Modificar o programa escolar torna-se a última opção para amenizar os problemas encontrados no Ensino de Ciências (como, por exemplo, a falta de tempo) porque a maioria dos professores entende que é indispensável preparar os alunos de nono ano para o ensino médio. Neste contexto, os conteúdos de Química, justificam, devem ser abordados, mesmo que superficialmente, pois é por isso que são trabalhados.

Nenhum nível de ensino atualmente deve ter como único objetivo a preparação para o próximo nível, uma vez que não há garantias de que os estudantes prosseguirão seus estudos. Muitas vezes, a preparação para os níveis posteriores de ensino acaba implicando no sucateamento da formação básica. Ao 
priorizar os níveis posteriores, os conhecimentos com aplicação imediata na vida ficam em segundo plano.

Como se percebe, o Ensino de Ciências do nono ano é marcado pela disciplinaridade e por um excesso de conteúdos de Química que prejudica e dificulta uma contextualização e abordagem mais profunda. Neste contexto, buscamos contribuir com uma proposta de ensino alternativa que amenize estes problemas e atribua um sentido diferente a esta fase do ensino, que não seja unicamente a preparação para o ensino médio. Para isso, buscamos apoio na ACT (FOUREZ, 1997).

\section{Alfabetização Científica e Tecnológica: buscando um novo porquê de ensinar Química no nono ano}

A expressão Alfabetização Científica e Tecnológica trata de uma metáfora que reporta à importância do que foi a alfabetização no século XIX e indica saberes, capacidades ou competências que, no mundo técnico-científico atual corresponde ao saber ler e escrever do passado (FOUREZ, 1997). Possui três principais finalidades ou objetivos pedagógicos (FOUREZ, 1997): a) no âmbito pessoal ou humanista, busca o posicionamento do indivíduo e o desenvolvimento de sua autonomia crítica diante do mundo técnico-científico atual; b) nos âmbitos cultural, social, ético e teórico, busca a comunicação entre os indivíduos, diminuindo as desigualdades originadas pela "falta de compreensão das tecnociências" (FOUREZ, 2002) e c) no âmbito econômico, busca o domínio e um melhor direcionamento dos conhecimentos.

Pretende-se que um indivíduo alfabetizado científico e tecnologicamente seja capaz de argumentar, negociar e dialogar com outros indivíduos, de enfrentar situações diversas e concretas de maneira racional, além de saber conduzir a relação entre saber-fazer e poder-fazer.

As capacidades desenvolvidas no processo de ACT são essenciais na conquista de um espaço na sociedade atual e na consolidação da democracia, onde todos possam ter condições de participar, se desejarem, de debates e decisões. Além disso, para que um país seja científica e tecnologicamente desenvolvido, é necessário que sua população compreenda e tenha conhecimentos básicos em Ciência e Tecnologia além de ter pessoas bem qualificadas nas áreas científicas. Nessa perspectiva, evita-se o ensino disciplinar e, entre os conteúdos de Ciências, são incluídos temas, questionamentos e problemas que desenvolvam essas atitudes e capacidades nos alunos. Dentre outros temas possíveis (MILARÉ; PINHO-ALVES, 2010a), escolhemos o tema Leite para basear nossa proposta de ACT para o Ensino de Ciências do nono ano.

Para que um indivíduo esteja científica e tecnologicamente alfabetizado, segundo Fourez (1997), é necessário desenvolver capacidades ou objetivos operacionais. 
A primeira delas está relacionada com o bom uso de especialistas, ou seja, de profissionais qualificados que prestam serviços em uma determinada área como, por exemplo, o médico, o mecânico, o eletricista, entre outros. O intuito é não deixar se enganar pelos especialistas, nem recorrer a eles de forma excessiva. Estas atitudes geram determinada autonomia e diminuem a dependência em um momento de decisão.

A segunda é a capacidade de fazer bom uso de caixas-pretas. O indivíduo deve saber quando e como é necessário se aprofundar em determinado conhecimento (abrir caixas-pretas, entendendo-se que o "desconhecido" é a caixapreta) para resolver situações ou por interesse cultural. Ter a ideia de qual conhecimento é pré-requisito de outro também é necessário e auxilia na escolha de quais caixas-pretas devem ser abertas ou permanecer fechadas.

O indivíduo deve saber utilizar modelos simples, isto é, ter a capacidade de construir modelos simples, pertinentes a determinado contexto e evitar sistemas complexos desnecessários à situação vivida. Isto porque ele deve compreender que o valor de um modelo depende de sua finalidade e do contexto em questão. Saber utilizar modelos simples é essencial na formação do pensamento científico, considerando que "fazer Ciência é formar uma representação simplificada e reducionista da complexidade do mundo" (FOUREZ, 1997, p. 68).

Ser capaz de utilizar e criar modelos interdisciplinares é outra habilidade necessária na ACT apresentada por Fourez (1997). Trata-se de desenvolver a capacidade de enfrentar situações, considerando elementos como observações, conhecimentos das mais diversas áreas, incluindo os da vida cotidiana, aspectos econômicos, éticos e políticos, além da consulta a especialistas.

Não são poucas às vezes em que se utilizam no Ensino de Ciências, seja durante as explicações do professor ou nos livros didáticos, metáforas, analogias e comparações. No dia-a-dia, elas comumente estão presentes nos meios de comunicação. Cabe também ao processo de ACT de um indivíduo, ajudá-lo a compreender e usar corretamente estas formas de expressão.

Outra capacidade relacionada à linguagem e expressão é o bom uso das traduções (FOUREZ, 1997, p. 73), ou seja, é desejável que o indivíduo saiba deslocar um problema de um contexto a outro, interpretar o significado de algo em diferentes momentos.

$\mathrm{Na}$ perspectiva da ACT, não basta ter os conhecimentos. É preciso desenvolver a capacidade de argumentar, negociar, utilizar os saberes na defesa de seu próprio posicionamento, seja diante de uma situação, durante uma conversa ou numa tomada de decisão. Trata-se dos critérios descritos como o bom uso da negociação e da articulação entre saberes e decisões.

Finalmente, é necessário que o indivíduo saiba diferenciar e fazer bom uso de aspectos técnicos, éticos e políticos conforme a necessidade imposta pelas situações em que vive. Não é adequado, por exemplo, utilizar argumentos e dados puramente técnicos em situações nas quais os aspectos éticos são mais apropriados. 
Parte-se da ideia de que estas competências podem ser desenvolvidas em sala de aula desde que os temas a serem abordados e a metodologia a ser utilizada sejam compatíveis com os pressupostos da ACT.

Neste contexto, o processo de escolha do programa escolar é importante. Segundo Fourez (1997, p. 29), "uma Alfabetização Científica e Tecnológica que se limita ao ensino de capacidades seria demasiadamente restrita. É necessário também eleger os conteúdos que serão ensinados". A relação das capacidades, ou seja, dos objetivos operacionais, atrelada aos três princípios ou objetivos pedagógicos da ACT (autonomia, domínio e comunicação), podem servir para delinear o que se deve trabalhar nas aulas de Ciências da educação básica.

Deste modo, a contribuição da ACT neste trabalho relaciona-se com orientações de como deve ser a estrutura da proposta de ensino elaborada, atribuindo novos objetivos ao Ensino de Ciências do nono ano. Algumas relações entre os objetivos da ACT, as atitudes que podem ser desenvolvidas e as contribuições do conhecimento químico para o desenvolvimento do tema Leite são apresentadas no Quadro 2. É necessário, no entanto, considerar que a abordagem de apenas um tema não esgota todos os objetivos da ACT.

Quadro 2: Possíveis relações entre os objetivos da ACT e os conhecimentos químicos

\begin{tabular}{|c|c|c|}
\hline Objetivos Operacionais da ACT & Descrição da Ação & Contribuição dos conhecimentos em Química \\
\hline Bom uso de especialistas & $\begin{array}{l}\text { Compreender boletins, notícias e declarações } \\
\text { de especialistas sobre } 0 \text { assunto. }\end{array}$ & $\begin{array}{l}\text { Conhecer as substâncias que compõem o leite e as } \\
\text { utilizadas nas fraudes e suas propriedades; } \\
\text { Compreender termos utilizados como pH, alcalinidade, } \\
\text { acidez, viscosidade, etc. }\end{array}$ \\
\hline Saber utilizar modelos simples & $\begin{array}{l}\text { Explicar possíveis transformações que } \\
\text { ocorrem com o leite. }\end{array}$ & $\begin{array}{c}\text { Reconhecer as evidências de ocorrência de reações } \\
\text { químicas (propriedades macroscópicas). }\end{array}$ \\
\hline Bom uso das traduções & $\begin{array}{l}\text { Utilizar em outros contextos o que foi aprendi- } \\
\text { do com o tema Leite. }\end{array}$ & $\begin{array}{c}\text { Conhecer as propriedades das substâncias e as } \\
\text { transformações. }\end{array}$ \\
\hline $\begin{array}{l}\text { Bom uso da negociação e articulação } \\
\text { entre saberes e decisões }\end{array}$ & $\begin{array}{c}\text { Tomada de decisões relativas à escolha do } \\
\text { tipo de leite para consumo e a posições frente } \\
\text { ao mito da reciclagem do leite. }\end{array}$ & $\begin{array}{l}\text { Conhecer a composição e as propriedades do leite; } \\
\text { Compreender os processos de separação de } \\
\text { componentes do leite. }\end{array}$ \\
\hline
\end{tabular}

\section{Contribuições da ACT ao Ensino de Ciências do nono ano}

Considerar os pressupostos da ACT para determinar os objetivos do estudo da Química no ensino fundamental pode ser uma proposta interessante e trazer bons resultados, uma vez que é uma forma de evitar o despejo massivo de conceitos e fórmulas de Química aos alunos. Também estimula o raciocínio, não exigido na manipulação simples de conceitos para resolver exercícios - muitas vezes a única aplicação do conhecimento estudado.

Uma proposta sob esta perspectiva de ensino não deve desconsiderar o desenvolvimento de conceitos-chave ou noções básicas essenciais no estudo das Ciências. Os próprios PCNs abordam a importância dos conceitos-chave, citando os conceitos de vida, sistema, energia, matéria, espaço, transformação, tempo e equilíbrio (BRASIL, 1998). É interessante promover nos alunos estas 
noções já estruturadas cientificamente e tão importantes para o aprendizado de conceitos e compreensões de fenômenos. Para o tema Leite, são destacados os conceitos-chave de Energia, Transformação e Matéria.

Os conteúdos estudados no nono ano também fazem parte do programa escolar da disciplina de Química do ensino médio, mostrando a ocorrência de uma antecipação de componentes curriculares e do caráter disciplinar da Ciência nas fases posteriores de ensino. Porém, para Fourez (1995, p. 105), cada disciplina possui como base "um certo número de regras, princípios, estruturas mentais, instrumentos, normas culturais e/ou práticas, que organizam o mundo antes de seu estudo mais aprofundado”. A definição destes parâmetros, característicos de cada disciplina, é essencial na construção dos pensamentos subsequentes, no desenvolvimento de seus conhecimentos, embora pareçam evidentes. E, "essa 'evidência' é um efeito que sobrevém somente após o estabelecimento de uma disciplina científica" (FOUREZ, 1995, p. 106, grifo do autor). Este estabelecimento não poderia ocorrer no ensino fundamental, onde o foco dado aos objetos de estudo deveria contemplar a Ciência como um todo. Para ser considerado alfabetizado científica e tecnologicamente, é preciso compreender os conhecimentos científicos em relação a noções provenientes de diversas disciplinas necessárias ao enfoque de contextos concretos. Para o estudo do tema Leite, por exemplo, a embalagem do leite pode ser explorada em sala de aula discutindo-se a composição do material (Química), massa, volume (Física) e aspectos higiênicos como processos de esterilização (Biologia).

O conhecimento científico deveria implicar em um saber-fazer e em um poder-fazer, pois pode melhor orientar as ações do indivíduo, proporcionando "um certo domínio e responsabilidade frente às situações concretas" (FOUREZ, 1997, p. 62). Na elaboração do programa escolar, os conteúdos escolhidos devem possibilitar uma ação mais apropriada e trazer certo domínio frente às situações da realidade. O conhecimento deve proporcionar ao indivíduo certa autonomia, uma "possibilidade de negociar suas decisões frente às pressões naturais ou sociais" (FOUREZ, 1997, p. 62).

Neste sentido, a problematização de situações cotidianas pode estimular o interesse e atribuir funcionalidade aos conhecimentos apresentados aos alunos. Como já discutido, os exemplos relacionados ao cotidiano apresentados nos livros didáticos não são suficientes. $\mathrm{O}$ uso de artigos de revistas e jornais, como muitos dos professores consultados fazem, pode contribuir na aproximação entre situações concretas e os conhecimentos estudados em sala de aula, promovendo um ensino contextualizado. $\mathrm{O}$ uso de reportagens e notícias sobre as fraudes no leite, por exemplo, é uma forma de problematizar e promover discussões entre os alunos sobre o tema.

Outro aspecto que não pode ser deixado de lado, ao se pretender promover a ACT, é a concepção construtivista da Ciência. Nesta perspectiva, a Ciência é encarada como uma construção humana dependente dos contextos histórico e social (FOUREZ, 1998). Em sala de aula, estas ideias sobre a Ciência 
podem ser desenvolvidas a partir da abordagem de aspectos históricos da Ciência e da Tecnologia.

Assim, alguns elementos decorrentes das análises dos documentos oficiais, dos livros didáticos e das entrevistas com os professores podem estruturar uma proposta de ensino sob a perspectiva da ACT. São eles: (a) Desenvolvimento dos objetivos da ACT; (b) Redução dos conceitos e conteúdos relativos à Química trabalhados no nono ano; (c) Desenvolvimento de conceitos-chave ou noções essenciais para a compreensão da Ciência; (d) Abordagem de aspectos históricos da Ciência e da Tecnologia; (e) Tratamento interdisciplinar das Ciências, evitando a fragmentação e a diferenciação das áreas científicas; (f) Abordagem temática; (g) Contextualização dos conteúdos trabalhados; (h) Aproximação entre o cotidiano, as ideias dos alunos e os conhecimentos científicos e (i) Possibilidade do uso dos conhecimentos na tomada de decisões (MILARÉ; PINHO-ALVES, 2010b). De modo geral, a proposta visa uma reconfiguração do Programa escolar do nono ano, atrelando novos objetivos ao Ensino de Ciências e, principalmente, ao estudo da Química (Quadro 3). A seguir, descreveremos um exemplo de abordagem interdisciplinar e de contribuição à formação da cidadania pela abordagem do tema Leite para o nono ano.

Quadro 3: Características do Ensino de Ciências sob a perspectiva da ACT e o praticado

\begin{tabular}{c|c|c}
$\begin{array}{c}\text { Aspectos do Ensino de } \\
\text { Ciências }\end{array}$ & $\begin{array}{c}\text { Ensino praticado no nono ano } \\
\text { (conforme dados obtidos) }\end{array}$ & $\begin{array}{c}\text { Ensino proposto na perspectiva da } \\
\text { ACT }\end{array}$ \\
\hline Programa Escolar & $\begin{array}{c}\text { Influência do Livro Didático } \\
\text { Disciplinar }\end{array}$ & $\begin{array}{c}\text { Abordagem temática } \\
\text { Interdisciplinar }\end{array}$ \\
\hline Objetivo & Preparar para o ensino médio & Desenvolver capacidades e atitudes \\
\hline Papel do ensino da Química & Introduzir noções para o ensino médio & $\begin{array}{c}\text { Compreender melhor um tema ou } \\
\text { problema estudado }\end{array}$
\end{tabular}

\section{Alfabetização Científica e Tecnológica pela abordagem do tema Leite}

O leite é um tema pertinente, pois trata de um alimento que os seres humanos consomem desde ao nascer. Além disso, com o avanço da tecnologia utilizada na indústria de alimentos, a variedade de embalagens, de sabores e de tipos de leite tem aumentado cada vez mais. No entanto, na maioria das vezes, o consumidor não consegue acompanhar estes avanços e não compreende sequer as descrições estampadas nos produtos que consome.

Considerando o tema e as características de um Ensino de Ciências que promova a ACT, alguns questionamentos tornam-se pertinentes. O que um aluno do nono ano precisa conbecer sobre o leite? De que forma conbecimentos sobre o leite permitem que um aluno exerça sua cidadania? Quais conhecimentos são necessários na compreensão e discussão de assuntos relacionados ao leite divulgados na midia? O que é necessário saber para armazenar, utilizar e consumir o leite adequadamente? Como compreender a relação entre a saúde e o consumo de leite? Que conhecimentos são necessários na escolha do leite a ser comprado, diante da grande variedade de produtos existentes no mercado? ${ }^{1}$ 
As respostas a estas questões ajudam na definição dos objetos de estudo. Em um primeiro momento, estas questões remetem à necessidade de se saber o que é o leite, qual sua origem e para que é utilizado. Depois, busca-se conhecer o processo de produção e sua composição, a fim de compreender os diferentes tipos de leite e seus derivados. A importância nutricional do leite e a compreensão das informações contidas nas embalagens de produtos ajudam a relacionar o consumo e a preservação da saúde das pessoas.

Procurando contemplar estes aspectos, foram estabelecidas relações entre os assuntos temáticos relacionados ao leite e os conteúdos escolares de Ciências, conforme apresentado no Quadro 4.

Quadro 4: Conteúdos escolares de Ciências para 0 estudo do tema leite

\begin{tabular}{|c|c|}
\hline Assunto temático & Conteúdos escolares de Ciências \\
\hline $\begin{array}{c}\text { Origem do leite } \\
\text { Importância no desenvolvimento dos mamíferos } \\
\text { Amamentação humana } \\
\text { Aspectos históricos de obtenção e consumo } \\
\text { Uso de tecnologias na obtenção do leite } \\
\text { Produção de leite no país; Importância econômica }\end{array}$ & $\begin{array}{l}\text { Classificação dos Seres Vivos } \\
\text { Características dos mamíferos } \\
\text { Cadeia Alimentar } \\
\text { Digestão } \\
\text { Calor e Temperatura }\end{array}$ \\
\hline $\begin{array}{c}\text { Processos industriais do leite } \\
\text { Etapas do processamento do leite } \\
\text { Tipos de leite } \\
\text { Derivados do leite } \\
\text { Embalagem } \\
\text { Fraudes no leite }\end{array}$ & $\begin{array}{c}\text { Microrganismos } \\
\text { Pasteurização (sobre Pasteur) } \\
\text { Transformações } \\
\text { Estados físicos; Mudanças de estado } \\
\text { Unidades de medida } \\
\text { Massa, Volume; Concentração } \\
\text { Energia (calorias) }\end{array}$ \\
\hline $\begin{array}{l}\text { Características e propriedades do leite } \\
\text { Composição do Leite } \\
\text { Propriedades físicas e químicas do leite } \\
\text { Consumo do leite } \\
\text { Importância nutricional } \\
\text { Armazenamento do leite } \\
\text { Custo }\end{array}$ & $\begin{array}{c}\text { Propriedades da Matéria Substâncias } \\
\text { Misturas; Separação de misturas } \\
\text { Diferenciação entre mistura e substâncias } \\
\text { Pirâmide Alimentar } \\
\text { Vitaminas, Sais Minerais } \\
\text { Importância do Cálcio } \\
\text { Doenças relacionadas à falta ou excesso de Cálcio }\end{array}$ \\
\hline
\end{tabular}

Nesta proposta, os conteúdos foram selecionados independentemente da disciplina científica às quais pertencem. Os conhecimentos se entrelaçam com o objetivo de desenvolver o assunto temático. Os assuntos provenientes da Biologia, Física e Química são ensinados sem a necessidade de separá-los no programa escolar, sendo, também, necessários alguns conhecimentos matemáticos. Nota-se que os conteúdos químicos foram reduzidos em favor de uma abordagem contextualizada e interdisciplinar.

Os conhecimentos não precisam ser tratados de forma linear. As diversas possibilidades de conexão entre eles permitem que, para um mesmo assunto, existam diferentes enfoques. A Figura 1 abaixo permite visualizar isso para o tema Leite. Nele, cada figura geométrica representa um tipo de conhecimento, tema ou subtemas e as setas e retas indicam as conexões entre eles. Os subtemas podem ser relacionados a outros conhecimentos, além dos indicados no Esquema. O subtema alimentação, por exemplo, pode ser enfocado pelo pro- 
cesso digestivo ou da nutrição, por exemplo. As chaves representam alguns dos itens que podem ser explorados, não esgotando todas as possibilidades.
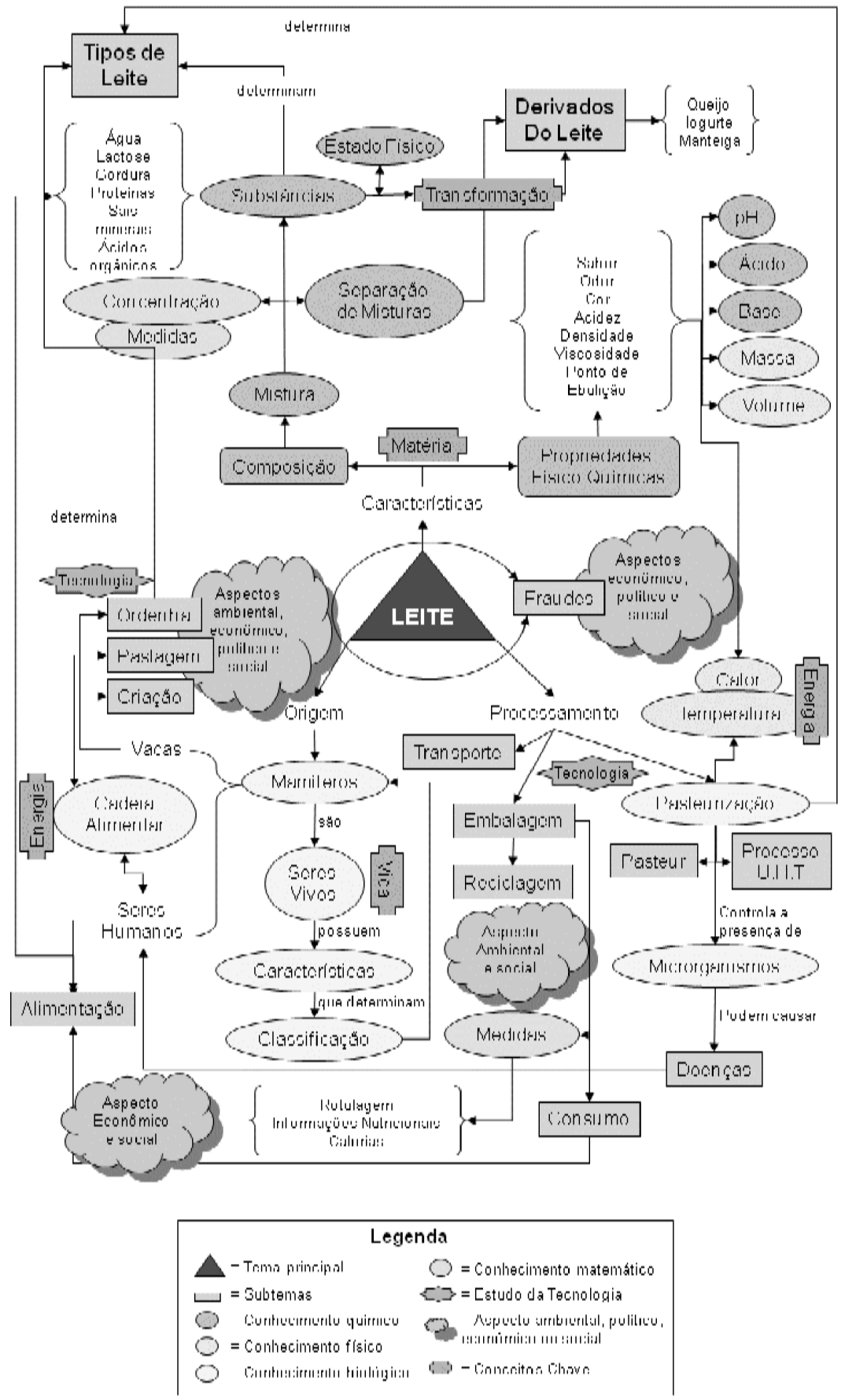
Os conceitos-chave também estão representados no Esquema, permeando diversos pontos, por serem necessários na compreensão de vários conceitos, subtemas e relação entre eles. Assim, a Energia está presente na abordagem da cadeia alimentar e da alimentação, da mesma maneira que para os processos industriais do leite. Neste sentido, o conceito-chave é trabalhado em diferentes momentos, contribuindo com o entendimento de sua complexidade e caráter unificador.

Além dos conteúdos disciplinares, é importante incluir aspectos sociais, políticos, econômicos e ambientais ao que é estudado (representado por nuvens na Figura 1). Para o tema leite, os aspectos sociais incluem, principalmente, a saúde das pessoas por possuir substâncias importantes para a alimentação humana. Estes pontos podem ser discutidos com base na vivência dos próprios estudantes, no consumo de leite e seus derivados em casa e na própria merenda escolar. O custo e a frequente variação de preços do leite no mercado são assuntos que relacionam aspectos econômicos e sociais, uma vez que interferem no consumo pelas famílias. A perspectiva ambiental pode ser tratada desde o impacto das pastagens e sua relação com o desmatamento de florestas até a reciclagem das embalagens de leite.

As fraudes do leite são outro assunto com potencialidade para se discutir aspectos políticos, sociais, econômicos e ambientais. É possível, por exemplo, focalizar as discussões nas ações dos órgãos governamentais para regularizar e fiscalizar a produção e a qualidade do leite que é consumido pela sociedade. Além disso, pode-se buscar compreender qual o papel do cidadão diante de situações como essa.

Os aspectos históricos podem compreender o contexto do trabalho de Pasteur, que não deve ser esquecido na abordagem do processo de pasteurização do leite. No que diz respeito às tecnologias, propõe-se discutir seu desenvolvimento na criação de gado leiteiro e ordenha, no processamento industrial do leite, na preparação de derivados do leite e na biotecnologia de modo geral.

É importante que no desenvolvimento do tema os estudantes precisem tomar alguma decisão ou postura diante de uma situação colocada pelo professor. Para o tema leite, os alunos poderão, por exemplo, emitir sua posição em relação a um alerta sobre a venda de leite reciclado ${ }^{2}$. Para isso, deverão considerar informações técnicas sobre a embalagem do leite, a posição ética das empresas e mercados, aspectos econômicos do processo, legislações, entre outros. A capacidade de argumentar, contra ou a favor, com base em conhecimentos será desenvolvida, evitando que informações fornecidas sejam apenas acatadas.

O tema envolve compreensões sobre diversos fatores para a tomada de decisões como consumidor. Afinal, diante da variedade de produtos no mercado, qual tipo de leite comprar? Como armazenar e quais procedimentos seguir antes de consumi-los? O leite mais caro é o de melhor qualidade? Por quê? Devese acreditar que os números no fundo da caixinha de leite representam a quantidade de vezes que ele foi reciclado? Estas e outras questões exemplificam deci- 
sões passíveis de reflexão de um consumidor exercendo seu papel de cidadão.

As estratégias de ensino devem ser compatíveis à perspectiva da ACT. Não seria adequado, por exemplo, abordar as propriedades da matéria seguindo exclusivamente os moldes do livro didático, sem estabelecer articulações entre este conteúdo e o tema abordado. Os debates, simulações e atividades experimentais, em um sentido investigativo em que ocorrem negociações, são mais propícios ao desenvolvimento da ACT.

Sugere-se também o uso de materiais diversificados de apoio e pesquisa e a consulta a especialistas como funcionários de órgãos fiscalizadores e indústrias, produtores, engenheiros e técnicos em alimentos, entre outros. Além de auxiliar no desenvolvimento da comunicação e na troca de informações, a aproximação entre especialistas e alunos favorece o conhecimento de diferentes campos de trabalho e carreira profissionais.

\section{A proposta na visão dos professores}

Cinco professores de Ciências do nono ano receberam um livrinho com a proposta desenvolvida e responderam um questionário para avaliação. A maioria dos professores concorda sobre a necessidade da abordagem interdisciplinar e é favorável à abordagem temática em Ciências. Entre as justificativas, está a melhora na compreensão e na assimilação, a aplicabilidade dos conceitos ensinados, os objetivos da disciplina, a necessidade de promover a cidadania e a maturidade e vivências insuficientes dos alunos para compreender o conteúdo sistematizado e fragmentado.

Quando questionados sobre a redução dos conteúdos no nono ano, dois professores se posicionaram contra a ideia, indicando a necessidade de mais aulas. O problema não estaria no excesso de conteúdos, mas no tempo de aula disponível. Este apontamento também esteve presente nas entrevistas. Mas, aumentar o número de aulas melhoraria a qualidade do Ensino de Ciências, mantendo-se o mesmo programa escolar vigente há décadas? Considerando todos os conteúdos do programa escolar, compatíveis com os do livro didático, o tempo para as aulas de Ciências realmente é insuficiente para uma abordagem adequada, superando o ensino tradicional (transmissão-recepção de conhecimento). Assim, não basta modificar apenas um dos elementos que compõe o cenário escolar. É necessária uma articulação entre o tempo disponível, o programa escolar, as condições de trabalho dos professores e as metodologias e objetivos do ensino.

Segundo as opiniões dos professores, pode-se concluir que o ponto crítico da proposta desenvolvida encontra-se no tempo necessário para desenvolvê-la. Uma resolução neste sentido requer um planejamento prévio e adequação dos temas nos objetivos do ensino e características do contexto escolar, o que compete aos profissionais que estarão em sala de aula. 


\section{Considerações Finais}

É necessária uma reflexão sobre os conteúdos de Química e sua forma de abordagem no nono ano do ensino fundamental. A antecipação de assuntos de maneira descontextualizada, sem outras aplicações visíveis além da resolução mecânica de exercícios, não acrescenta muito na formação dos estudantes desta fase do ensino. Ao contrário do desejado, ela pode reforçar a aprendizagem de conceitos equivocados e despertar desinteresse pela Química no ensino médio.

$\mathrm{Na}$ proposta, foram selecionados alguns conhecimentos de Química, assim como de outras áreas da Ciência, de maneira a auxiliar na compreensão de aspectos diversos do tema Leite. A proposta apresentada está aberta, sujeita à agregação de novos fatores, à adaptação a outros cenários e a outras modificações que se fizerem necessárias em sala de aula. O exercício de desenvolvê-la mostrou que é possível fugir da mesmice do programa pregado pelos livros didáticos, contribuir para com a Alfabetização Científica e Tecnológica e dar um sentido mais comprometido aos conteúdos de Ciências. 


\section{NOTAS}

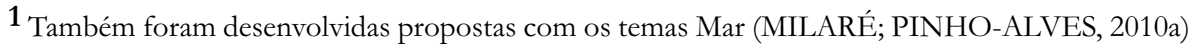
e Cana-de-açúcar (MILARÉ, 2008).

2 Uma mensagem amplamente divulgada na Internet alerta sobre a reciclagem do leite. O processo consistiria em repasteurizar o leite com prazo de validade vencido e colocá-lo novamente à venda nos supermercados. Para que as empresas de leite tivessem controle sobre a quantidade de vezes em que o leite foi repasteurizado, um número de 1 a 5 seria impresso na base da embalagem. (Fonte: http://www.e-farsas.com/corrente_leite.htm acesso em Fevereiro de 2008).

\section{REFERÊNCIAS BIBLIOGRÁFICAS}

AMARAL, I. A. Currículo de Ciências: das tendências clássicas aos movimentos atuais de renovação in: BARRETO, E. S. S. (org). Os currículos do Ensino Fundamental para as Escolas Brasileiras. $2^{\mathrm{a}}$ ed. Campinas, SP: Autores associados; São Paulo: Fundação Carlos Chagas, 2000. p. 201-232.

BARDIN, L. Análise do conteúdo. Lisboa: Edições 70 LDA, 1977.

BRASIL. Lei de Diretrizes e Bases da Educação Nacional. Brasília: 1996.

BRASIL. Secretaria de Educação Fundamental. Parâmetros Curriculares Nacionais: Ciências Naturais / Secretaria de Educação Fundamental. - Brasília: MEC / SEF, 1998. 138p.

DOMINGUES, J. L.; KOFF, E. D. \& MORAES, I. J. Anotações de leitura dos Parâmetros Nacionais do Currículo de ciências in: BARRETO, E. S. S. (org). Os currículos do Ensino Fundamental para as Escolas Brasileiras. $2^{\mathrm{a}}$ ed. Campinas, SP: Autores Associados; São Paulo: Fundação Carlos Chagas, 2000. p. 193-200.

FOUREZ, G. A construção das Ciências: introdução à filosofia e à ética das ciências. trad. Luiz P. Rouanet. São Paulo: Editora da Unesp, 1995. 319p.

FOUREZ, G. Alfabetización Cientifica y Tecnológica. Argentina: Ediciones Colihue, 1997.

FOUREZ, G. Saber Sobre Nuestros Saberes: un léxico epistemológico para la enseñanza. Traducción: Elsa Gómez de Sarría. Buenos Aires: Ediciones Colihue, 1998. 200p.

FOUREZ, G. Crise no Ensino de Ciências. Investigaçoes em Ensino de Ciências, Porto Alegre, 2002.

FURIÓ, Carlos \& FURIÓ, Cristina. Dificultades conceptuales y epistemológicas en el aprendizaje de los procesos químicos. Educación Quimica, v. 11, n. 3, p. 300-305, 2000.

LIMA, M. E. C. C. \& SILVA, N. S. A Química no Ensino Fundamental: uma proposta em ação in: ZANON, L. B. \& MALDANER, A. M. (org). Fundamentos e propostas de ensino de química para a educação básica no Brasil. Ijuí: Ed. Unijuí, 2007, p. 89-108.

MALDANER, O. A. et al. Currículo contextualizado na área de Ciências da natureza e suas tecnologias: a Situação de Estudo in: ZANON, L. B. \& MALDANER, O. A. Fundamentos e Propostas de Ensino de Química para a Educaşão Básica no Brasil. Ijuí: Ed. Unijuí, 2007. p. 109-138.

MILARÉ, T. Conteúdos de Química e livros do Ensino Médio: análise reflexiva dos conteúdos e abordagens. 2005. 34f. Trabalho de Monografia - Instituto de Química, Universidade Estadual Paulista "Júlio de Mesquita Filho", Araraquara, 2005.

MILARÉ, T. Ciências na $8^{a}$ série: da Química disciplinar à Química do Cidadão. 2008. 213p. Dissertação. (Mestrado em Educação Científica e Tecnológica). Universidade Federal de Santa Catarina, Florianópolis-SC, 2008.

MILARÉ, T. \& PINHO-ALVES, J. Do ensino disciplinar à formação interdisciplinar da cidadania no Ensino de Ciências. Educación Quimica, v. 23, n. 1, 2010a.

MILARÉ, T. \& PINHO-ALVES, J. A Química disciplinar em Ciências do $9^{\circ}$ ano. Quimica Nova na Escola, v. 32, n. 1, 2010b.

MORTIMER, E. F. Concepções Atomistas dos estudantes. Quimica Nova na Escola, n. 1, 1995.

ROSA, M. I. F. P. S. \& SCHNETZLER, R. P. Sobre a importância do conceito transformação química no processo de aquisição do conhecimento químico in: Química Nova na Escola, n. 8, nov., 1998.

SANTA CATARINA. Secretaria de Estado da Educação e do Desporto. Proposta Curricular de Santa Catarina: Educação Infantil, Ensino Fundamental e Médio: Disciplinas curriculares. Florianópolis: 
COGEN, 1998. 244p.

SÃO PAULO. Secretaria da Educação. Proposta Curricular do Estado de São Paulo: Ciências. São Paulo: SEE, 2008. 64p.

ZOTTI, S.A. Organização do Ensino Primário no Brasil: uma leitura da história do currículo Oficial. 2006. Disponível em: <http://histedbr.fae.unicamp.br> Acesso em: Abril 2006.

Data recebimento: $18 / 01 / 2009$

Data aprovação: 05/01/2010

Data versão final: $25 / 03 / 2010$ 